\title{
American Medicine and the Politics of Race
}

Maxwell Gregg Bloche

Georgetown University Law Center, bloche@law.georgetown.edu

This paper can be downloaded free of charge from:

https://scholarship.law.georgetown.edu/facpub/722

48 Persp. Biology \& Med. S54-S67 (2005)

This open-access article is brought to you by the Georgetown Law Library. Posted with permission of the author. Follow this and additional works at: https://scholarship.law.georgetown.edu/facpub

Part of the Civil Rights and Discrimination Commons, Health Law and Policy Commons, and the Law and Politics Commons 


\title{
A M E R I C A N M E I C INE ANDTHE POLITICS OF RACE
}

M. GREGG BLOCHE

\begin{abstract}
Straw men play a major role in the debate over racial disparity in American medicine. Most have been deployed by the disparities-denying right, but progressives intent on "outing" racism have sent forth their share. This essay flushes out the straw men while attempting to understand the competing moral premises that drive the politics of health care disparity. At bottom, arguments about the scope of disparity and discrimination in medical care are disputes about the appropriate scope of personal responsibility for life circumstances. Further research into the factors that correlate with racial differences in health care can shed light on the circumstances that bring about these differences. Whether these circumstances, once understood, should be deemed acceptable is a moral and political matter, and sharp differences over the scope of personal and public responsibility for these circumstances are inevitable. Such disagreements, however, distract us from efforts to reach common ground solutions to agreed-upon inequities in health care.
\end{abstract}

$\mathrm{R}$

ICHARD EPSTEIN CHARACTERIZES the Institute of Medicine report on racial disparities (Smedley, Stith, and Nelson 2003) as both a "genteel guilt trip" and "a determined effort to make things appear worse than they really are" (Epstein 2005). Since the politics of race are hardly genteel, I shall take this as a

Professor of Law, Georgetown University; Adjunct Professor, Bloomberg School of Public Health, Johns Hopkins University.

Correspondence: Georgetown University, McDonough Hall, Room 451, 600 New Jersey Avenue NW, Washington, DC 20001.

E-mail: bloche@law.georgetown.edu.

Perspectives in Biology and Medicine, volume 48, number 1 supplement (winter 2005):S54-S67

(C) 2005 by The Johns Hopkins University Press 
compliment. ${ }^{1}$ The IOM report has become a subject of much sound and fury. Critics on the right have attacked the authors' motives, condemned the authors for being too quick to diagnosis discrimination, and insisted that racial disparity in health care remains unproven. Some on the left, meanwhile, have criticized the IOM for failing to diagnosis pervasive racism in American medicine.

Allegations of racism attract attention, and the charge that America's physicians are biased against blacks and Latinos has drawn considerable press coverage. But disparities-denying conservatives have found welcoming audiences in high places. Last year, top officials at the Department of Health and Human Services ordered HHS researchers to strike the term disparity from a Congressionally mandated annual report on- "health care disparities" (Bloche 2004). Officials told the researchers to delete their conclusion that racial disparities are "pervasive in our healthcare system" and to remove findings of disparity in care for cancer, cardiac disease, AIDS, asthma, and other illnesses. The researchers complied. Two days before Christmas, HHS Secretary Tommy Thompson released a neutered rewrite, one that rejected the IOM's findings of racial disparity and dismissed the "implication" that racial "differences" in care "result in adverse health outcomes" or "imply moral error ... in any way."

Unhappy HHS officials then leaked earlier versions of the report. Irate House and Senate Democrats insisted that Thompson retract the rewrite and issue the researchers' suppressed version in its stead. In February 2004, Thompson did so, telling a Congressional hearing that the rewrite had been a "mistake." This, in turn, disappointed disparities-deniers, who chided Thompson for failing to maintain a stand against political correctness.

All sides in this debate have deployed straw men, though the disparities-denying right has assembled them in greater numbers. I will devote some effort in this essay to flushing them out. But my larger aim is to understand the ire. To this end, I will search for the competing moral premises that inspire conflict over whether racial disparities in health care are a problem and what the state should do about them. At bottom, I contend, arguments about the scope of disparity and discrimination in medical care are disputes about the appropriate scope of personal responsibility for life circumstances. Further research into the factors that correlate with group differences in health care can shed light on the circumstances that bring about these differences. But whether these circumstances, once understood, should be treated as unjust or inevitable (or even as a matter of just dessert) is a moral and political matter. Those wedded to an ethic of individual responsibility and self-reliance, unleavened by sensitivity to unlucky life circumstances, differ sharply from those more concerned with fair distribution of life's possibilities and misfortunes.

${ }^{1}$ I was a member of the IOM committee responsible for the report and was one of the principal drafters of the chapters that assessed the mechanisms by which racial disparities arise. 


\section{STRAW MEN}

Straw men heavily populate the essay by Sally Satel and Jonathan Klick in this issue, and they make their presence felt in Richard Epstein's piece. Some examples follow.

\section{Insurance Coverage and Ability to Pay}

At the outset, Satel and Klick (2005) portray the IOM report as emphasizing "discrimination" and underplaying access to quality care as a cause of racial disparities. Epstein does the same. But the IOM report begins by noting that access, in the form of insurance coverage, is the main determinant of racial differences in care, since the quality and extent of coverage vary by race (Smedley, Stith, and Nelson 2003). The IOM Committee on Racial and Ethnic Disparities directed its attention elsewhere at Congress's request. The legislation that created the Committee (and led to its report) instructed the IOM to "Assess the extent of racial and ethnic differences in health care that are not otherwise attributable to known factors such as access to care (e.g., ability to pay or insurance coverage)" (emphasis added), and to "Evaluate potential sources of racial and ethnic disparities in health care, including the role of bias, discrimination, and stereotyping at the individual (provider and patient), institutional, and health system levels."

Thus the Committee sought to factor out differences in insurance coverage, income, wealth, and other access-related influences, and to focus on racial and ethnic disparities among patients with similar coverage and ability to pay. The Committee recognized that racial and ethnic disparities, though substantial, are small by comparison to differences between the care that insured and uninsured Americans receive. The panel also noted that health status - as opposed to health care-disparities mostly reflect differences in behavioral risks, social and economic circumstances, and environmental conditions. Medical care by itself has surprisingly small effects on population-wide health.

\section{Uncertainty and Discretion}

Epstein, Satel, and Klick erect another straw man by misportraying the IOM Committee's explanation for racial disparities in care that persist after insurance and other access-related factors are taken into account. Epstein writes that the Committee's report "lumps together the questions of clinical uncertainty and communication breakdown with bias and prejudice," and evinces "eagerness to find (illicit) discrimination as the source of the various difficulties." Satel and Klick make similar claims. They thereby fail to engage, let alone rebut, the Committee's explanation.

The Committee's explanation invokes two kinds of uncertainty: that arising from incomplete information about diagnostic and therapeutic alternatives, and that stemming from shortcomings in doctor-patient communication (Balsa et. al. 2003). The first, in my view, is the most important. Clinical judgment is beset by pervasive uncertainty about diagnosis and prognosis, the efficacy of tests and 
treatments, and patient preferences (Wennberg 1985). More often than not, medical decisions don't rest solidly on scientific evidence and physicians choose from among multiple clinical alternatives. Wide variations in medical practice ensue, leaving doctors with a great deal of clinical discretion. To the extent that physicians exercise this discretion in ways that vary by race or ethnicity in the aggregate, racial and ethnic differences in heath care ensue. Among the many factors that can influence the exercise of discretion are race-linked heuristics, attitudes, and levels of empathy. The cognitive psychology literature contains ample proof that race-linked heuristics, attitudes, and differences in empathy persist. To be sure, as John Wennberg and others note, other influences, including geography, affect the exercise of discretion (Baicker, Chandra, and Skinner 2005). But some of these influences may themselves be race-linked: patterns of housing segregation, for example, mean that the effects of geography and race can be correlated, mutually reinforcing, and difficult to disentangle.

Epstein, Satel, and Klick heap invective on this line of reasoning instead of probing its recesses. They might have posed questions, not addressed in the IOM's report, about when race-linked heuristics should merit deference (on clinical or other grounds) and when they should be rejected as offensive or inaccurate stereotypes. They also might have explored the trade-offs between gains from reducing clinical discretion (and group disparities in care) by imposing rules and the clinical advantages of bedside discretion. In addition, they could have examined the role of patients - their expressed preferences and levels of trust-in shaping physicians' clinical judgments.

Uncertainty stemming from shortcomings in doctor-patient communication gets more sympathetic treatment from Epstein than from Satel and Klick. Epstein is open to the possibility that communication failure matters and that cultural and linguistic gaps make it more likely. Satel and Klick speak mockingly of a "“cultural competence training' industry," and they misportray the IOM's discussion of linguistic and cultural gaps as a diatribe against racial bias. The IOM's hypothesis concerning shortcomings in doctor-patient communication is, in essence, this: (1) communication is imperfect (due to time limits, economic constraints, and ambiguities in the meaning of language and other cues); (2) communication across racial and ethnic lines is especially prone to errors and uncertainty because of language and cultural gaps; (3) physicians are therefore more uncertain about minority group members' medical needs and concerns; and (4) physicians are therefore less inclined to offer at least some high-intensity, highcost treatments to minority group members. As a corollary, patients separated from their doctors by language and cultural gaps are more uncertain about the quality and reliability of their doctors' recommendations. Faced with this greater uncertainty, these patients are (on rational grounds) less inclined to agree to recommended treatments or to seek medical consultation in the first place.

This account of physician-patient communication explains racial disparity, to some degree, at least, without invoking racial bias. Satel and Klick refuse to ac- 
knowledge this; Epstein allows for the possibility but doesn't pursue its policy implications. These implications are straightforward. Approaches that Satel and Klick ridicule, including cultural competence-building and better representation of disadvantaged minority groups in the health professions, hold out great potential to shrink race- and ethnicity-related gaps in doctor-patient communication. So does physician payment reform that better rewards effort spent talking and listening to patients. Even skeptics about the import of racial bias have reason to support these approaches as part of an effort to ameliorate health care disparities. For some on the right, however, ideological blinders get in the way.

\section{Variations in Clinical Circumstances}

Yet another straw man, proffered by Epstein, Satel and Klick, and others, is the claim that the IOM Committee failed to acknowledge that legitimate, racerelated differences in care can arise from variations in clinical circumstances. Differences in disease incidence, drug metabolism, treatment efficacy, patient preferences, and family support systems sometimes correlate with race. Good, patient-centered clinical decision making should take such factors into account, even if they result in race-related variation. The IOM report took note of this.

Epstein, Satel, and Klick could have pushed the discussion forward in this sphere by challenging the IOM and others to do better at distinguishing between clinical differences that do and do not justify racially disparate treatment. There are gray zones in this realm, worthy of further exploration. One is patient preferences. Conventional bioethics thinking holds that the choices of mentally competent patients merit great deference. But it is well known that these choices are greatly influenced by how doctors frame and portray clinical alternatives. They are also shaped by patients' social circumstances, including community-wide levels of trust. To the extent that these influences themselves reflect race-related unfairness, formulaic deference to patient choice cannot be the whole answer. But how should health policy - and the law-address disparities that arise from these influences? The role of family support systems raises similar issues. To the extent that weaker social support systems in minority communities ensue from historical injustice, medical decision making that takes account of available social support may be both clinically appropriate and morally problematic. This conundrum of health policy and social justice merits deeper exploration.

\section{Minority Physicians' Beliefs and Attitudes}

Epstein, Satel, and Klick also err by assuming that minority physicians are not influenced by stereotypes or bias when they care for patients who belong to their own racial or ethnic group. This premise plays a key role in their critique: based on it, they contend that proof of racial bias in clinical decision making requires a showing that white and minority physicians treat minority patients differently. This assumption is understandable - the notion that black or Latino doctors can hold negative stereotypes or biased attitudes toward their compatriots is coun- 
terintuitive. But evidence from cognitive psychology studies shows that members of minority groups often hold unfavorable beliefs and biases toward fellow group members. A variety of mechanisms for this have been proposed, including incorporation of ideas and attitudes that prevail in the wider society and identification with members of favored groups (and with their beliefs and biases). Both of these mechanisms may be especially relevant for minority physicians anxious about their social status and eager for acceptance by their white peers. If minority physicians share their white peers' beliefs and biases toward minority group members, then requiring proof that they treat minority (or white) patients differently than do white physicians makes no sense.

\section{Discrimination and Racism}

The claim that health care disparities are the product of pervasive racism is a caricature promoted, for the purpose of ridicule, by the disparities-denying right. Some, though, have invoked the IOM report as proof of pervasive racism in medicine, and a few press reports have characterized the IOM's conclusions in such terms. In fact, the IOM report avoided the word racism, and many have criticized this omission as a failure to fully acknowledge racial injustice and its causes. Overt racism-apartheid beliefs (consciously experienced and actedupon) about the relative respect and regard owed to whites and to racial minority groups - is part of the health care disparities equation: it persists on the fringes in American life. But it is not the main plotline.

There is little evidence that American physicians, as a group, openly harbor and act upon race-based hatred or contempt. There are outlier cases of crude bigotry, but preoccupation with these distracts attention from the larger story. Clinical uncertainty and discretion, race-related heuristics and attitudes, and communication failures across cultural and linguistic lines interact in complex ways to create disparity. The word racism is a conversation-stopper-an epithet that delivers a harsh judgment. Harsh judgment is at times warranted: calling a bigot a bigot achieves a measure of corrective justice and affirms the human dignity of those who are objects of the bigot's contempt. But wielding the "r-word" against race-related heuristics, attitudes, and differences in empathy that are both widespread and subliminal, even subconscious, in America is more likely to arouse ire than to encourage self-scrutiny and inspire change. To ameliorate disparities, consciousness-raising scrutiny of causal mechanisms will be essential. Facile resort to the "r-word" makes such scrutiny less likely.

\section{SUBSIDIES AND MORALS:}

\section{WhEN ARE RACIAL DIfFERENCES WRONG?}

The chief pity of the right's resort to straw men is that they divert attention from conservatives' more potent objection to policies aimed at ameliorating racial disparities in care. Part of the foundation for the conclusion that disparities are 
widespread is the large number of studies that find disparities after controlling for insurance status, income, education levels, and other confounding factors. Epstein, Satel, and Klick attack this foundation by pointing to potential confounding influences that go unobserved (and uncorrected for) in these studies. Racial disparities, they note, appear to narrow as additional confounding variables are identified and factored out. They extrapolate from this argument to the conclusion that unobserved variables, associated with race, explain all apparent racial disparities. Decisions by doctors and patients, Epstein argues, take myriad unobserved costs and benefits into account. Because some of these correlate with race, race-related differences in care ensue.

For Epstein, all racial differences in care that result from differential costs and benefits are legitimate per se. Some accuse him of thereby countenancing racism. His response is that markets select against racial prejudice to the point of extinguishing it. Racist sellers charge more than non-racists to serve members of the racial out-group, since racist sellers seek compensation for the affront to their bigoted tastes. But this price difference, Epstein holds, is the racists' undoing, since it channels patrons to cheaper, non-racist sellers. Well-functioning markets, Epstein says, provide immunity against racial animus, and in medicine, markets function well enough. Excessive government regulation, not bigotry, keeps markets from fulfilling their antiracist potential.

This is an appealing story. The American Way, with a few right turns, prevails over the bigots in the end. Dismissing this account as racist, as some do, is a resort to epithet, not reason. Epstein's story, though, sidesteps an anomaly at the outset. This anomaly points the way to a deeper problem, unacknowledged by those at either pole of the disparities debate.

The anomaly is that open racism-segregation, exclusion, and race-based contempt - was pervasive in American life at a time of comparative laissez faire. Racial segregation and exclusion in economic life, including medicine (Smith 1999), was a matter of choice, not just Jim Crow law. Sellers of myriad goods and services, including health care, chose to sacrifice profits in order to discriminate openly. ${ }^{2}$ The emergence of antidiscrimination laws and antiracist social norms during the 1960s and 1970s coincided with the intensification of economic and health and environmental regulation more generally. This is not to say that such regulation accounts for the fade of overt racism since the 1950s; it is merely to note that markets made room for racial animus for much of our history.

Does this disprove Epstein's account? To the contrary, it shows that Epstein hasn't pushed his story far enough. His central claim is that race-related differences in behavior, including health care disparities, result from race-related dif-

${ }^{2}$ One might argue that some sellers were not in fact sacrificing profits by discriminating, since failure to exclude victimized racial groups might have led to backlash and boycotts by white purchasers. This argument underscores the insufficiency of laissez faire as a remedy for discrimination based on racial animus. 
ferentials in costs and benefits. But he hesitates to "count" bigotry as a basis for cost - the psychic cost bigots experience from treating members of disfavored groups with equal respect. Epstein is not a racist, and he treats bigotry as an illegitimate preference; this buttresses his wishful thinking about the ability of markets to extinguish bigoted behavior. By not "counting" bigoted preferences - and the psychic costs of violating them-he clears a path for his claim that racial disparities are legitimate market outcomes that reflect race-related cost differences.

This is a provocative proposition as it stands, but it would turn offensive were Epstein to "count" racial animus as a preference and to therefore treat bigoted behavior as the legitimate product of differential costs. To avoid doing so, he distinguishes (implicitly) between differential costs that do and do not count. For Epstein, overt bigotry does not count, but, it seems, virtually every other raceassociated factor does.

The problem with this approach is that it fails to explain how lines are to be drawn between the factors, or costs, that do and do not count. Indeed, Epstein doesn't acknowledge the need to draw such lines; instead, he merely ignores the psychic costs suffered by disappointed bigots whom markets (or law) won't let discriminate. But surely these costs are real for the bigots. Deciding not to count them is a moral and political judgment-one that virtually all of us would agree upon, but a political choice nonetheless. Likewise, deciding to count other racerelated factors, as Epstein does, and to treat the racial disparities that result from them as legitimate, is a political judgment.

Others may and do disagree with this judgment. Many different costs, or variables, can contribute to racially disparate outcomes by influencing people's market choices. Some, as Epstein, Satel, and Klick note, are difficult to observe and probably have not been accounted for in studies of health care disparities. Epstein could and should have pushed his story further by explaining all racially disparate results as products of differential costs, then noting the need for political choices between acceptable and illegitimate differentials in cost.

Had Epstein done so, he would have had to acknowledge that differential costs do not make disparate outcomes legitimate per se. Discovery that a previously unrecognized differential cost, or unobserved variable, contributes to racial disparity does not in itself shrink the problem of disparity: it sets up the need for a political and moral judgment as to whether the newly recognized factor should be accepted as a given or targeted for amelioration. This judgment is often easy to make. For example, nearly all would agree that a physician's race-related empathy or dislike is cause for objection and reason for action. ${ }^{3}$ Likewise, nearly all would hold that race-correlated differences in disease presentation and drug metabolism can justify differences in diagnostic and therapeutic strategies. Other

\footnotetext{
${ }^{3}$ There might, however, be disagreement over the proper scope and content of government intervention-e.g., over whether government should pursue primarily punitive, educational, or other approaches.
} 
factors, however, are politically and morally contested. Should race-correlated differences in family psychosocial support, patient trust, and therapeutic compliance be tolerated or treated as morally unacceptable? ${ }^{4}$ Answers to such questions depend on views about social justice. Do past ill treatment of minorities and present social, cultural, and economic differences create moral duties to address gaps in family structure and social capital? How much should government intrude into the private sphere in order to tackle such problems, and how much economic redistribution should the state impose? Are trust and compliance, and their psychological determinants, a state responsibility, perhaps because of past government failures to address abuses of trust?

Other politically contested factors reflect the differential abilities of white and disadvantaged minority populations, in the aggregate, to pursue their needs and wants within health care systems (Bloche 2001). There is evidence that African Americans are less inclined to press their needs, to complain, and to sue when health plans and providers disappoint them. The resulting cost differentials for payers and providers create incentives to deliver more intensive services to whites. It is, of course, not the case that all whites are more assertive or demanding than all blacks: these cost differentials represent population-wide trends. These trends, though, are enough to instill expectations in heuristic fashion, and to make it economically rational for payers and providers to act on these heuristics by delivering lower levels of care to African Americans. Should the health care disparities that result be dismissed as matters of personal preference, not public responsibility? Or should government intervene, in the face of cost differentials, either to push payers and providers to compensate for African American reticence or to encourage black patients to more vigorously pursue their needs?

Epstein does not acknowledge, let alone address, these and other political questions about the morality of disparity. He sidesteps such questions by adopting the principle of actuarial fairness, the premise that differential costs justify health care disparities per se. He avoids embarrassment by making an exception for the differential psychic costs that bigots experience on encountering members of groups they don't like, but he doesn't explain his basis for this exception.

Epstein's embrace of actuarial fairness sets up his most far-reaching claim: that government action to ameliorate disparities entails coerced cross-subsidies. Antidiscrimination laws triggered by disparate racial impact are his paradigmatic case. To comply with these laws, Epstein notes, actors must incur costs that they otherwise wouldn't. For example, applying a disparate impact standard to health plans would press them to ignore the cost differentials (and business opportuni-

\footnotetext{
${ }^{4}$ It is frequently suggested that physicians are more reluctant to prescribe onerous courses of treatment for patients with weaker home and family support systems. In addition, the IOM report pointed to racial and ethnic differences in patient preferences (influenced in part by patient trust and manifested in part by patient compliance) as part of the explanation for racial and ethnic differences in care.
} 
ties) created by race-related differences in patient assertiveness. To the extent that antidiscrimination law causes plans to act differently than they would were they free to respond to race-related cost differentials, it creates a cross-subsidy, from less assertive to more assertive racial groups.

From an actuarial fairness perspective, such cross-subsidies are wrong: differential costs should be taken as givens, not shifted between groups. But other conceptions of fairness yield different verdicts on intergroup subsidies. Moral objection to pervasive, race-related disadvantage, in health and other spheres, leads to refusal to take race-linked cost differentials as givens-and to insistence on crosssubsidies that arouse Epstein's ire. Objection to racial disparity in rescue efforts leads to insistence on equity in health care provision even when disparities in care do not yield differences in clinical outcomes. ${ }^{5}$ Objections to socio-economic disparity in health or in rescue efforts give rise to calls for other intergroup subsidy schemes-schemes that overlap considerably but not completely with programs aimed at racial inequity.

Epstein does not make the case for preferring actuarial fairness to these other grounds for judging cross-subsidy schemes, nor does he acknowledge the case against it. The case for actuarial fairness is tied to the value of allowing differential costs to remain with the groups that incur them. ${ }^{6}$ Doing so has value when group members and others can respond meaningfully to these cost signals by adjusting their behavior in a socially desirable fashion. Auto insurance is the paradigmatic example: different rates for drivers with different safety records encourage drivers to take care. Actuarial fairness has another, noninstrumental value: the morality of reciprocity supports leaving higher costs with those who voluntarily create them. In the health care disparities context, actuarial fairness yields little of either of these forms of value. Providing disparate levels of care to people with different levels of social support, trust and assertiveness, expected likelihoods of compliance with treatment, and ease of communication with clinical caretakers is unlikely to spur improvements in social support, trust and assertiveness, or these other things. And the morality of reciprocity hardly supports "punishing" disadvantaged minorities for their deficits (actual or perceived) in these areas by giving them lower levels of medical care. In the health care disparities realm, actuarial fairness is a principle unmoored from its rationale.

\footnotetext{
${ }^{5}$ Epstein assumes that the measure of medical care's value is its impact on health: the number of lives or life-years saved (perhaps adjusted for quality of life) per dollar spent or organ transplanted. But given the reality that medicine has relatively little effect on population-wide health by comparison with lifestyle, socioeconomic influences, and other environmental factors, it is implausible to understand social spending on medical care solely in terms of its impact on health. Medical care matters at least as much because people and societies ascribe independent value to attempted rescue. Rescue, daringly conceived and courageously executed, affirms the individual's dignity and import for society, even when rescue fails (Bloche 2003).
}

${ }^{6}$ More precisely, these costs are spread, but within separate groups, without cross-subsidies between groups. 
Yet Epstein's core insight-that racial disparities in care reflect differential costs - retains its power. If Epstein has not taken the next step, toward a way to distinguish between acceptable cost differentials and those that merit intervention to ameliorate disparities, neither have activists in the campaign against disparities. Some supporters of robust remedial measures treat the disparities that remain, after income and insurance status are factored out, as wrongful, racebased discrimination. To do so is to avoid the task of identifying the mechanisms that contribute to disparity and making political and moral judgments about the acceptability of disparities arising from each.

Consider, for example, physician reliance on stereotypes, a pejorative term for heuristics. Heuristic reasoning is unavoidable in all endeavors characterized by uncertainty and by complexity that exceeds limited information processing capacity (Todd and Gigerenzer 2000). Medical practice surely qualifies (Bloche 2003). Heuristics can be wrong, but they are often remarkably accurate-that is, they yield results close to those produced by more systematic, comprehensive reasoning processes. To the extent that race-related differences in patient assertiveness, treatment compliance, family support systems, and other clinical variables exist, heuristics that reflect them will be accurate. To put the point more baldly, some race-related stereotypes are valid. This makes categorical rejection of racial stereotypes problematic, something civil rights-oriented progressives (including me) don't like to think about. ${ }^{7}$ Saying no to inaccurate racial stereotypes is a simple matter. Rejecting a valid heuristic makes no sense unless its use-or its result-so offends that the cost of invoking it outweighs the cognitive efficiencies it yields.

To reject all race-based heuristics as cases of wrongful discrimination is to take the categorical position that all carry costs greater than their efficiencies. This forecloses nuanced consideration of what to do when a stereotype is both noxious and valid. Acknowledging this possibility — and the quandary it presentsdoes more than open the way for reluctant use of a stereotype that may have value under particular decision making constraints. It also clears a path for candid exploration of the factors that lend validity to the stereotype. Better understanding of these factors can, in turn, aid efforts to ameliorate inequities that lie behind the stereotype.

An illustration is the stereotype that African American patients have more fragmented family support systems than whites and are therefore less able to sustain the stresses of intensive and disabling treatment courses. This stereotype may well be incorrect, and even if it is accurate on a population-wide basis, reliance

\footnotetext{
${ }^{7} \mathrm{~A}$ high-visibility example of this problem is the debate over profiling for airline security purposes. Rejection of profiling policies that are based on inaccurate thinking as to which nationalities are high-risk is easy; objections to the profiling of, say, young Saudi men, who are more likely than grandmothers from Iowa to be hijackers, are less compelling. Subjecting grandmothers from Iowa to the same security precautions as Saudi men will raise costs (with little security payoff), unless equity is achieved by reducing the precautions taken for Saudi men (which would reduce security).
} 
on it may be inefficient: a modest effort to learn something about each patient's home life may yield better information at minimal cost. To the extent, though, that it is accurate, it highlights the importance of paying attention to black patients' support systems. ${ }^{8}$ The availability of social support is relevant to the decision to begin a disabling or agonizing course of treatment-even if taking social support into account yields racially disparate decisions. And sensitivity to weaknesses in African American family support systems can help clinical caretakers to take "affirmative action," case by case, to fill gaps in family support so all can benefit from vigorous therapies. Beyond this, awareness of the consequences of family breakdown in the medical setting can fuel efforts to strengthen families through educational opportunity, job creation, high-quality child care and preschool, and other proven strategies (Moynihan 1986).

Other sources of racial disparity likewise merit closer scrutiny, in order to learn more about causal mechanisms and to decide which ones do and don't merit remedial action. Americans are bound to differ over how to make these decisions, since we disagree about the proper scope of personal responsibility and the extent of society's obligation to address historical and institutional inequities. But we should have that debate, and it is unhelpful to dismiss those who take a broad view of personal responsibility and a narrow view of public obligation as racists or proponents of discrimination. Those, like me, who hold that racial and other inequities of opportunity are society's concern should go about the work of winning over our fellow citizens (especially those who vote) without suggesting that those who see things differently are apologists for bigotry.

\section{TOWARD COMMON GROUND SOLUTIONS}

Progress on disparities is possible through programs built on common ground. There is wide agreement that universal medical coverage would go most of the way toward eliminating racial disparities in care. Health insurance, like auto insurance, should be a personal obligation, though public subsidies will be needed to make it affordable to all (Calabrese and Rubiner 2004). Required coverage, moreover, should include services shown to promote health as well as early detection and treatment of disease. Framing the problem of health care disparities as more a quality-of-care matter than a civil rights issue would reduce political polarization and make health plans and providers less defensive. Clinical outcomes research and state-of-the-art quality measurement and management methods can and should target disparities. In the years ahead, market and political pressures will push plans and providers to do so, as America's workforce and electorate become increasingly multiracial. The same pressures are also likely to

\footnotetext{
${ }^{8}$ It is, of course, also important to pay attention to other patients' support systems. But if this stereotype is accurate, there will be a higher "yield" from inquiring into African American patients' support systems.
} 
encourage more vigorous efforts to bridge cultural and language barriers to communication and to effective use of health systems by disadvantaged Americans.

Yet a key pathology of American politics will remain an obstacle to progress. Since 1968, the right has fallen into the habit of seeking votes by stoking working-class racial and cultural resentment. Success at the polls has been addictive. In national elections, millions of working-class whites vote against their own and their families' economic interests, in favor of candidates hostile to federal health, education, and other opportunity-creating programs. This electoral alchemy has aligned economically distressed whites with well-off Americans intent on tax cuts-and against disadvantaged minorities who benefit from programs these candidates aim to cut.

Were this alliance to fray, tax-slashing politicians (and their wealthy beneficiaries) would fare less well at the polls. Race and culture are the ties that bind, by dividing. Hard-pressed whites bitter over black and Latino advantages, real or perceived, blind themselves to the concerns they and minorities share. From the right's perspective, keeping this bitterness alive, and championing it, are important. Opposing affirmative action, disputing claims of race-based disadvantage, and objecting to vigorous antidiscrimination laws send the desired political signals. Caricaturing concerns about racial disparities in health care and ridiculing proposed solutions are consistent with this approach. Dispensing with caricatures in order to search for common ground would depart sharply from it. ${ }^{9}$

Liberals participate in this polarizing dynamic. Common ground solutions, especially universal coverage, will require the well-off to sacrifice. For privileged Americans with progressive politics, it is easier-and certainly cheaper-to take the side of the "good guys" by speaking out against racial discrimination than it is to campaign for the large-scale redistribution (through taxes) that universal coverage would require. For many baby boomer progressives, being liberal on social and cultural issues (including race) but tight-fisted on fiscal matters has become a point of pride. This means, in practice, strong support for affirmative action and antidiscrimination law enforcement — and desultory effort, at best, on behalf of universal coverage and other initiatives that target core inequalities of opportunity in American life. ${ }^{10}$ This stance takes on the "bad guys," and polar-

\footnotetext{
${ }^{9}$ This is not to say that commentators who deny the existence of racial disparities and dispute claims of racial injustice are consciously pursuing a political strategy. The likelier basis of their positions is the congeniality between conservative moral premises (in particular, heavy emphasis on personal responsibility) and political strategy, and the selection (by conservative think tanks, media, and other institutions with the power to amplify some voices and dismiss others) of spokesmen who both believe and effectively articulate the requisite message.

${ }^{10}$ Examples of other such initiatives include equalization of resources per pupil across rich and poor public school districts (current struggles between liberals and conservatives over such matters as vouchers and school choice obscure this larger inequality); universal, high-quality preschool; and intensive mentoring and tutoring programs for children from disadvantaged neighborhoods.
} 
izes debate, on racial matters while insulating economic privilege against redistributive politics.

The American debate over racial inequity thus has a Kabuki quality. In health as in other policy spheres, ritualized struggle over the scope of discrimination and the propriety of race-conscious remedies masks a shared aversion to more basic, opportunity-creating change. Polarization protects privilege, in part by setting working-class Americans against each other. There is need and possibility for a new progressive politics - a politics that highlights financially stressed Americans' shared needs and tackles inequities of opportunity, but that respects personal success. Such a politics can yield common ground solutions that go most of the way toward ending racial disparity in medical care. But the Kabuki politics of racial polarization will be a daunting obstacle to overcome.

\section{REFERENCES}

Baicker, K., A Chandra, and J. S. Skinner. 2005. Geographic variation in health care and the problem of measuring racial disparities. Perspect Biol Med 48(Suppl):S42-S53.

Balsa, A. I., et. al. 2003. Clinical uncertainty and healthcare disparities. Am J Law Med 29: 203-19.

Bloche, M. G. 2001. Race and discretion in American medicine. Yale J Health Policy Law Ethics 1:95-131.

Bloche, M. G. 2003. The invention of health law. California Law Rev 91:247-322.

Bloche, M. G. 2004. Health care disparities: Science, politics, and race. N Engl J Med 350: 1574-76.

Calabrese, M., and L. Rubiner. 2004. Universal coverage, universal responsibility: A roadmap to make coverage affordable for all Americans. Washington, DC: New America Foundation.

Epstein, R. 2005. Disparities and discrimination in health care coverage: A critique of the Institute of Medicine study. Perspect Biol Med 48(Suppl):S26-S41.

Moynihan, D. P. 1986. Family and nation. New York: Harcourt.

Satel, S., and J. Klick. 2005. The Institute of Medicine report: Too quick to diagnosis bias. Perspect Biol Med 48(Suppl):S15-S25.

Smedley, B. D., A.Y. Stith, and A. R. Nelson, eds. 2003. Unequal treatment: Confronting racial and ethnic disparities in health care. Washington, DC: National Academies Press.

Smith, D. B. 1999. Health care divided: Race and healing a nation. Ann Arbor: Univ. of Michigan Press.

Todd, P. M., and G. Gigerenzer. 2000. Simple heuristics that make us smart. Behav Brain Sci 23:727-80.

Wennberg, J. E. 1985. On patient need, equity, supplier-induced demand, and the need to assess the outcome of common medical practices. Med Care 23:512-20. 